\title{
RozDZial 11
}

\section{Analiza sieci społecznych jako metoda badania kultury organizacyjnej}

\author{
Jolanta Bieńkowska*
}

\subsection{Wprowadzenie}

Pod wpływem dynamicznych zmian techniczno-społecznych przestrzeń organizacyjna ulega ewolucji. Radykalnie zmienia się charakter poszczególnych jej elementów [zob. Sikorski, Bieńkowska 2014]. Dominujące na przestrzeni dziesięcioleci struktury hierarchiczne pod wpływem rosnących wymagań rynku zaczęły przekształcać się w kierunku konfiguracji elementów organizacji według procesów, co umożliwiło skuteczne zaspokajanie rosnących potrzeb klientów. W kolejnym etapie organizacje, dążąc do uelastycznienia relacji z kooperantami, zaczęły implementować rozwiązania sieciowe [Kulpa-Ogdowska 2006, s. 139]. Natomiast kultura organizacyjna z restrykcyjnego strażnika porządku organizacyjnego przeobraziła się w enklawę partycypacji i kreatywności, ostatecznie hołdując autonomii i pragmatycznemu podejściu do organizacji przedsięwzięć [Koźmiński 2013, s. 56]. Podążając za zmianami w zakresie zarządzania organizacjami, należy poszukiwać metod i narzędzi badawczych, które pozwolą zilustrować tok zmian, jak również oddadzą aktualny, dynamiczny charakter przestrzeni organizacyjnej. Celem niniejszego rozdziału jest przedstawienie analizy sieci społecznych jako użytecznej metody badania kultury organizacyjnej właściwej do opisywania dynamiki procesów społecznych zachodzących obecnie w jej obszarze.

\subsection{Analiza sieci spolecznych (SNA)}

Sieć społeczna powstaje w wyniku nawiązywania pomiędzy ludźmi kontaktów, mających podłoże szeroko rozumianego współdziałania (wspólnej realizacji zadania, dzielenia się zasobami, a także udzielania wsparcia emocjonalnego).

\footnotetext{
* Dr, adiunkt, Uniwersytet Łódzki, Katedra Zarządzania.
} 
Odzwierciedla ona strukturę powiązań łączących poszczególnych członków zbiorowości [Batorski 2008, s. 167] i zależności przyczynowo-skutkowe procesów społecznych zachodzących wewnątrz grupy.

Mimo że pojęcie sieci społecznych zostało zdefiniowane kilkadziesiąt lat temu, dopiero obecnie cieszy się dużą aplikacyjną popularnością. Stało się to za sprawą rozwoju najpopularniejszego współcześnie kanału informacyjnego, jakim jest Internet [Kadushin 2012, s. 4] oraz światowej sławy portalu społecznościowego - Facebooka [Pryke 2012, s. 1], którego zadaniem było ułatwienie szybkiego nawiązywania znajomości (social network). To miejsce spotkań w przestrzeni wirtualnej czytelnie zobrazowało istotę sieci społecznych, dzięki czemu wpłynęło nie tylko na wzrost zainteresowania kształtowaniem relacji międzyludzkich w układzie sieciowym, lecz także zmieniło charakter sieci społecznych. Dotąd obszarem budowania więzi interpersonalnych była przede wszystkim sfera prywatna, a dominującym sposobem ich nawiązywania - bezpośrednie spotkania. Tak samo było w zakresie budowania relacji zawodowych [zob. Marody, Giza-Paleszczuk 2004, s. 152-153]. Dziś zasięg sieci społecznych jest niewspółmiernie większy, jak też bardziej dynamiczny. Nawiązywane relacje społeczne są nietrwałe i uwarunkowane pragmatyką, a nie - jak dotąd przywiązaniem emocjonalnym.

Sieci społeczne stały się przedmiotem badań naukowych w okresie międzywojennym, kiedy to zaczęło wzrastać zainteresowanie psychospołecznymi aspektami działalności ludzkiej. Metodyczne podwaliny badania sieci społecznych stworzył J. Moreno, który w latach 30. XX wieku opracował technikę socjogramu [Wasserman, Faust 1994, s. 77] służącą identyfikacji pozytywnych i negatywnych postaw interpersonalnych $\mathrm{w}$ grupie [Brzeziński 1980, s. 287]. Jednak pojęcia sieci społecznych jako pierwszy użył J. A. Barnes w 1954 roku, badając strukturę relacji międzyludzkich [Knoke 2008, s. 8-9]. W toku dalszych prac badawczych opracowana została metoda empirycznej weryfikacji założeń przebiegu procesów grupowych, zwana analizą sieci społecznych SNA (Social Network Analysis) lub analizą sieciową, służąca mapowaniu relacji społecznych w danej grupie [Dasgupta 2006, s. 359]. Opiera się ona na teorii grafów oraz algebrze macierzowej [Stępka, Subda 2009]. Pozwala na badanie grupy w oparciu o diagnozowanie procesów w niej zachodzących. Celem jej zastosowania jest ilustrowanie interakcji pomiędzy poszczególnymi członkami grupy (bądź odnotowywanie ich braku). Charakteryzuje się zatem dynamicznym, procesowym podejściem do analizy struktury zbiorowości, co zilustrowano na rys. 11.1. 


\section{Exploration \& Production}

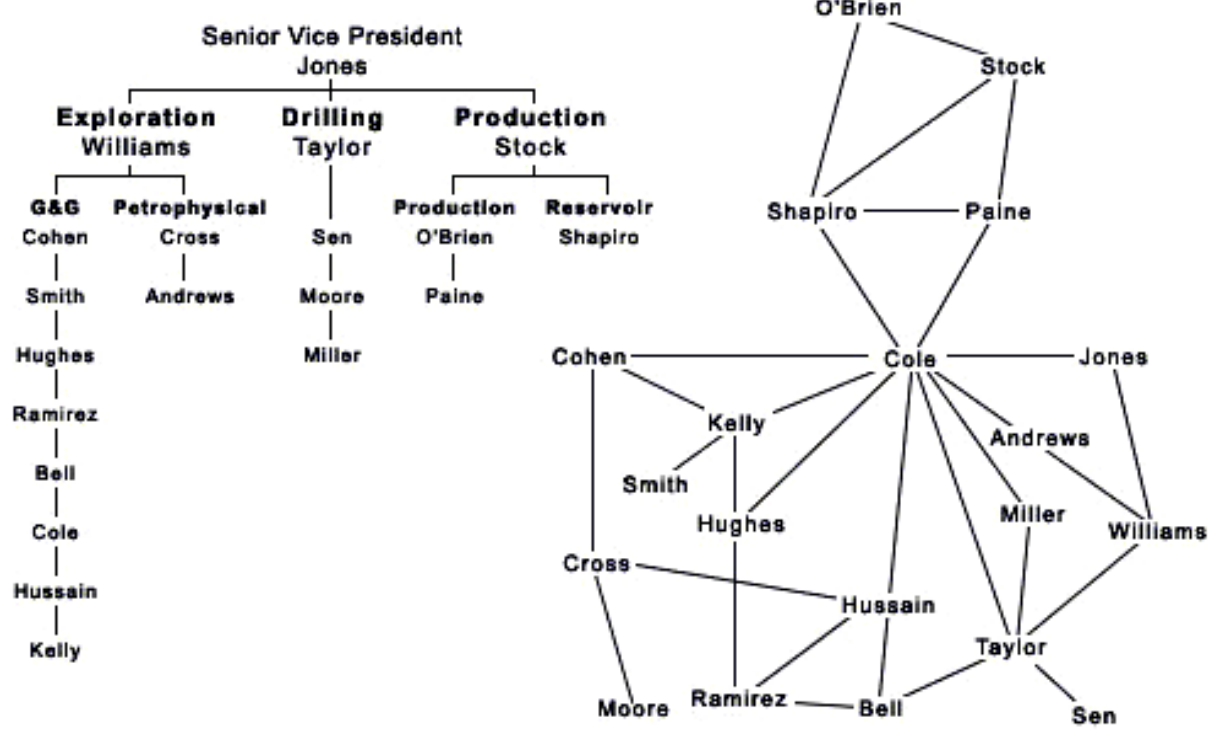

Rysunek 11.1. Struktura sieci

Źródło: http://www.robcross.org/network_ona.htm (dostęp 30.04.2014)

Definicja operacyjna sieci społecznych ujmuje je jako zbiór aktorów połączonych ze sobą układem relacji [Klimas 2013, s. 229]. Aktorami mogą być jednostki, zespoły, organizacje oraz zdarzenia. Założeniem analizy sieci społecznej jest diagnozowanie relacji między aktorami, a nie przypisywanie atrybutów samym aktorom [Stępka, Subda 2009], co determinuje jej dynamiczny charakter. Badane relacje odzwierciedlają kierunek i natężenie interakcji pomiędzy dwoma bądź większą liczbą podmiotów, przedmiotów, cech itd. [Chmielewska, Kołodziejczyk 2013, s. 122]. Wśród typów relacji społecznych będących przedmiotem badania można wymienić: współpracę, rywalizację, afiliację, konflikt, podział władzy, komunikację, dzielenie się wiedzą, przepływ dóbr, itp. [Wasserman, Faust 1994, s. 18].

Podstawą prowadzenia analizy sieciowej jest zbieranie informacji na temat występowania powiązań między uczestnikami zbiorowości. Punktem wyjścia jest zdefiniowanie aktorów, czyli wskazanie kto lub co (ludzie, organizacje, zdarzenia itp.) zostanie zakwalifikowany do próby. Kolejnym krokiem jest określenie typu relacji będących przedmiotem analizy oraz dokonanie operacjonalizacji zmiennych poprzez wyróżnienie obserwowalnych wskaźników, które pozwolą wyeksponować badane zależności [Juszczyk 2001, s. 34]. 
Zbieranie danych odbywa się najczęściej za pomocą kwestionariusza ankiety lub wywiadu. Później, na podstawie zgromadzonego materiału pierwotnego, budowana jest macierz sąsiedztwa, w której liczbę wierszy i kolumn wyznacza liczba aktorów poddanych badaniu, natomiast wartościami elementów macierzy mogą być zero-jedynkowe zapisy świadczące o wystąpieniu relacji lub jej braku albo wartości wag krawędzi [Koszelew 2011, s. 1-2, 4]. Zobrazowano to w tab. 11.1 i na rys. 11.2.

Tabela 11.1. Macierz podobieństwa

\begin{tabular}{|c|c|c|c|c|c|}
\hline & A & B & C & D & E \\
\hline A & - & 0 & 1 & 0 & 1 \\
\hline B & 0 & - & 1 & 0 & 1 \\
\hline C & 1 & 1 & - & 1 & 1 \\
\hline D & 0 & 0 & 1 & - & 0 \\
\hline E & 1 & 1 & 1 & 0 & - \\
\hline
\end{tabular}

Źródło: opracowanie własne.
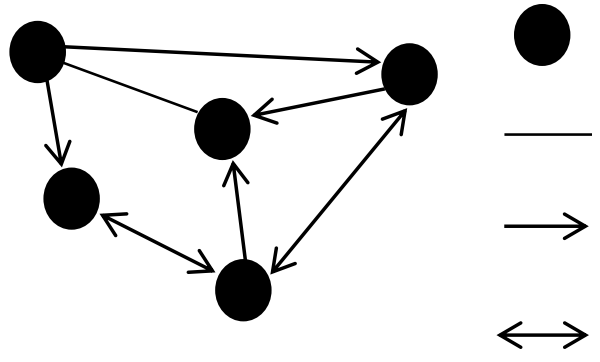

węzeł

relacja nieskierowana,

np. ta sama forma prawna

relacja skierowana jednostronna,

np. przepływ finansowy

relacja skierowana dwustronna,

np. transfer wiedzy

Rysunek 11.2. Schemat grafu

Źródło: opracowanie własne na podstawie: Klimas [2013], s. 230

Prezentacji danych na temat badanych relacji dokonuje się za pomocą grafu, którego podstawowymi elementami składowymi są wierzchołki (aktorzy) oraz krawędzie (relacje) [McCulloh, Armstrong, Johnson 2013, s. 4]. Ilustruje on strukturę badanej grupy. Jego walorem jest czytelność uzyskana dzięki bezpośredniemu, symbolicznemu przekazowi zawartych w nim informacji. Wzrokowa analiza grafu nasuwa pierwsze, wstępne wnioski z badania. 
Pogłębioną analizę relacji społecznych wykonuje się na podstawie mierników, które można przyporządkować do poziomów analizy sieci. W odniesieniu do całej sieci ocenie poddaje się m.in. jej wielkość, gęstość, stabilność, podobieństwo (poziom makro). Wyodrębnienie na podstawie rysunku grafu zbiorów węzłów (podgrup) implikuje badanie spójności sieci (poziom mezo). Natomiast na poziomie poszczególnych węzłów stosuje się mierniki mówiące o: stopieniu węzłów, centralności, pośrednictwie w tworzeniu ścieżki, bliskości oraz wektorze własnym (poziom mikro) [Klimas 2013, s. 241-243].

Metoda analizy sieci społecznych nie jest jak dotąd powszechnie stosowana w nauce o zarządzaniu (szczególnie w Polsce), w której do weryfikacji przyjętych hipotez stosuje się najczęściej metody badań statystycznych opartych na analizie korelacji lub badania jakościowe [Sułkowski 2008, s. 18]. Posiada ona jednak duży potencjał i pozwala na poznanie przebiegu procesów społecznych, mających zasadniczy wpływ na sprawność funkcjonowania organizacji. W opracowaniach dotyczących studiów sieci organizacyjnych pojawia się termin Organizational Network Analysis (ONA), pod którym kryje się adaptacja analizy sieci społecznych (SNA) służąca badaniu relacji biznesowych oraz sieci wewnątrzorganizacyjnych (m.in. zdolności adaptacyjnych organizacji, procesu podejmowania decyzji, integracji międzyorganizacyjnej po fuzji, procesu innowacji czy znajdowania lidera w zespole) [zob. www.orgnet.com].

\subsection{Nowa perspektywa badania kultury organizacyjnej}

Kultura organizacyjna jest pojęciem wykorzystywanym do wyjaśniania wpływu procesów społecznych na sprawność działania systemu organizacyjnego [Griffin 2004, s. 180]. Przypisuje się jej funkcję stymulatora efektywnych zachowań organizacyjnych [Griffin 2004, s. 182], jak również regulatora zachowań uczestników, pozwalającego zachować równowagę organizacji [Koźmiński 2004, s. 181].

Pojęcie kultury organizacyjnej opiera się na opisie relacji społecznych kształtowanych zgodnie z wartościami i normami kulturowymi charakterystycznymi dla danej organizacji [Sułkowski 2002, s. 58]. Jej charakter odczytuje się ze stylów sprawowania władzy organizacyjnej, dominujących form komunikowania się, wzorów dzielenia się wiedzą, poziomu spójności grup, obowiązujących regulacji zachowań w sytuacjach nieoczekiwanych [zob. Hofstede 2000, s. 50]. Zatem kultura oparta jest na sieci społecznej zawiązanej w danej organizacji. Z kolei rozpatrując istotę sieci społecznej z punktu widzenia kryterium nawiązywania relacji, jakim jest wspólnota wyznawanych norm i wartości oraz wzajemnego zaufania [Krupski (red.) 2003, s. 344], nasuwa się wniosek, że są to zagadnienia opisujące to samo zjawisko społeczne $\mathrm{z}$ różnych perspektyw badawczych. 
Stosowana powszechnie metodyka badania kultury organizacyjnej została opracowana na popularnych zarówno w antropologii, jak i socjologii założeniach, że zjawisko kultury ma charakter inercyjny [Zbiegień-Maciąg 1999, s. 17], w związku z tym proces jej ewolucji przebiega długofalowo, a organizacje zachowują charakter postfiguratywny - pokolenia młodsze przyswajają wartości i wzory zachowań starszych, utrzymując status quo grupy [Kulpa-Ogdowska 2006, s. 148]. Stąd też rezultaty badań nad kulturą mówią przede wszystkim o atrybutach danej zbiorowości, a nie o procesach społecznych w niej zachodzących [Sikorski 1998, s. 56].

Taki sposób przyjęcia założeń postępowania badawczego w naukach o zarządzaniu (nie tylko w odniesieniu do kultury organizacyjnej) miał uzasadnienie $\mathrm{w}$ epoce przemysłowej oraz $\mathrm{w}$ czasach wczesnego modernizmu, kiedy dynamika zmian techniczno-społecznych była niska lub umiarkowana, a granice między system organizacyjnym a otoczeniem wyraźnie zarysowane [Czarnecki 2011, s. 160]. Powszechnie praktykowane wówczas statyczne ujęcie kultury organizacyjnej skupiało się na poszukiwaniu wzorów zachowań społecznych, służących jako narzędzie generalizowania oceny postępowania członków zbiorowości, do której wzory te się odnoszą. Turbulentność otoczenia zmieniła perspektywę badawczą także wobec aspektu kulturowego organizacji. Kultura, pozostając w ścisłej interakcji z pozostałymi elementami systemu, reaguje na częste zmiany uelastycznianiem zachowań organizacyjnych.

U podstaw zmiany charakteru kultury organizacyjnej leżą: globalizacja i związana z nią otwartość gospodarcza oraz mobilność zawodowa, zdobycze techniki informacyjnej, a także zyskujący na popularności model sieciowej organizacji przedsięwzięć biznesowych. Narodziny gospodarki globalnej zainicjowały migrację na szeroką skalę osób aktywnych zawodowo. W pierwszej kolejności przedstawiciele firm podejmujących kooperacje w innych krajach zaczęli przenosić się w nowe lokalizacje. Później, pojawiający się deficyt na lokalnych rynkach pracy pobudził mobilność zawodową i podejmowanie decyzji o poszukiwaniu miejsca pracy poza granicami ojczystego kraju. Tym samym pokłosiem globalizacji stała się problematyka wielokulturowości organizacji [zob. Koźmiński 2004, s. 182]. Obecność osób reprezentujących inne wartości, wzory myślenia i działania inicjuje modyfikację dotychczasowych, utrwalonych i zakorzenionych schematów postępowania.

Innym czynnikiem ewolucji kultury są nowe kanały informacyjne, na czele z Internetem, które skłaniają do nawiązywania relacji społecznych i zawodowych między przedstawicielami różnych kultur, wskutek czego dochodzi do wypracowania zasad uniwersalnych, ponadkulturowych [Paleczny 2007, s. 214], znoszących granice my-oni, charakterystyczne dla dotychczasowego utożsamiania zjawiska kultury [Rozkwitalska 2010, s. 59]. 
Dążenia organizacji do zachowania efektywności działania zaczęły skłaniać do podejmowania decyzji o zawężaniu zakresu działania do realizacji zadań podstawowych oraz o nawiązywaniu krótkoterminowych relacji współpracy. Aktualnie podejmowanie kolejnego projektu tożsame jest $\mathrm{z}$ nawiązywaniem nowych kooperacji $\mathrm{z}$ wyselekcjonowanymi pod względem ekonomiczności i korzystności partnerami, niezależnie od ich umiejscowienia na globie. Granice między organizacją a otoczeniem stały się ultraelastyczne, gwarantując swobodę wejścia i wyjścia w strukturę sieci [Barczak 2010, s. 216]. Zatem jest to kolejna determinanta unifikacji zachowań, w tym także zachowań organizacyjnych.

Konieczność wypracowania efektywnych wzorów współpracy ponad organizacyjnymi, narodowymi granicami sprawia, że kultura organizacji nie może być już ujmowana w przeważającej mierze atrybutowo przez pryzmat cech odróżniających ją od innych [Sułkowski 2008, s. 19], gdyż zważywszy na powyższe argumenty dochodzi do szybkiej dezaktualizacji prezentowanych za ich pośrednictwem informacji. Kultury ewoluują w kierunku elastycznych zasad regulacji stosunków społecznych oraz heterogeniczności [Sikorski 2008, s. 45]. W konsekwencji tych przemian może zyskać na popularności dynamiczne traktowanie zjawiska kultury organizacyjnej [Kostera, Glinka 2011], bowiem interesujące wydaje się rejestrowanie: przebiegu zmian, odczytywania wzorów zdobywania wiedzy, poszukiwania kontrahentów, podejmowania wspólnych decyzji oraz finalizowania projektów realizowanych w oparciu o rozwiązania sieciowe. Potencjał wysokich walorów poznawczych posiada też obserwacja naturalnych zmian kulturowych zachodzących u poszczególnych uczestników sieci. Wyjście naprzeciw zmianom zasad funkcjonowania organizacji otwiera możliwość zastosowania analizy sieci społecznych w diagnozowaniu kultury organizacyjnej.

\subsection{Zastosowanie SNA do badania kultury organizacyjnej}

Analiza sieci społecznych (SNA) ze względu na odrzucenie rozpoznawania atrybutów aktorów na rzecz poznania dynamiki i charakteru relacji pozwala na odejście od nadawania kulturom etykiet, prezentujących w obecnych uwarunkowaniach krótkoterminowe informacje, na rzecz badania wzorów zachowań. Umożliwia aplikację podejścia procesowego do kultury organizacyjnej, diagnozowanie procesów społecznych w kontekście efektywności organizacji.

Kultura organizacyjna w swej naturze opiera się na podejściu dynamicznym. Jest żywym organizmem, reagującym na bodźce zarówno wewnętrzne, jak i zewnętrzne. Obrazuje złożoność relacji międzyludzkich, dlatego zastosowanie metody analizy sieciowej pozwoliłoby odzwierciedlić procesy, które konstytuują organizację. Projektując zastosowanie SNA do badania kultury organizacyjnej, można przyjąć wiele perspektyw badawczych na poszczególnych poziomach w zależności od celu poznania, który wyznacza zakres sieci, wskazując aktorów wchodzących w jej skład. 
Badanie sieci jako całości sugeruje przyjęcie trzech obszarów badawczych. Dwa pierwsze polegają na utożsamianiu sieci z organizacją, natomiast ich rozróżnienie opiera się na kryterium trwałości więzi organizacyjnych.

Pierwsze, tradycyjne ujmowanie sieci jako organizacji odnosi się do nawiązywania trwałych więzi opartych na długotrwałym uczestnictwie, dotychczas przeważającym w większości organizacji. W tym przypadku analiza sieci społecznych pozwala na zbadanie poziomu homogeniczności kultury. Definiując kulturę organizacyjną, zakłada się, że jest ona systemem znaczeń podzielanych przez wszystkich członków danej zbiorowości [Fryzeł 2005, s. 4]. Założenie o spełnieniu warunku jednorodności kulturowej jest dyskusyjne i dzięki diagnozowaniu stopnia upowszechnienia określonych norm zachowań (spójności sieci) jest możliwa jego empiryczna weryfikacja. Tym samym staje się możliwa ocena siły kultury.

Na potrzeby analizy procesów społecznych zachodzących w organizacji wyróżnia się dwa typy związków interpersonalnych: formalne i nieformalne. Za pomocą analizy sieci społecznych ułatwione jest poznanie specyfiki ich obu, a także porównanie ich podobieństwa lub rozbieżności na wielu płaszczyznach, m.in.: struktury władzy (identyfikacja liderów nieformalnych), porównanie oficjalnych i nieoficjalnych kanałów informacyjnych służących dzieleniu się wiedzą [Chmielewska, Kołodziejczyk 2013, s. 122], czy też ujawniania istnienia klik w zespole zdaniowym [Wysieńska 2012, s. 8].

Analiza sieciowa może być również zastosowana na etapie tworzenia kultury (badania rozprzestrzenia się wartości i norm postępowania) lub obserwowania zachowań w przypadku konkretnych zdarzeń, jak np. przyjęcia nowego pracownika lub reakcji na sytuację kryzysową. Przyjęcie takiej perspektywy badawczej pozwala na poznanie mechanizmów życia kultury.

Drugie ujęcie - poziomu makro - wychodzi naprzeciw aktualnym rozwiązaniom strukturalnym, polegającym na tworzeniu tymczasowych sieci wspólpracy międzyorganizacyjnej. Przyjęcie takiego zakresu badanej zbiorowości umożliwiałoby m.in. weryfikację hipotezy o unifikacji wartości i norm zachowań na terytorium krajów pozostających we współpracy gospodarczej [Przytula 2011, s. 29], jak również poznanie kryteriów doboru kooperantów, którymi mogą być wykluczające się wyznaczniki: zaufanie albo ekonomiczność. W takim ujęciu studiować można także zachowania twórców sieci (network weavers) [Wysieńska, 2012, s. 7], których zadaniem jest poszukiwanie pomostów, inicjowanie ich powstawania, śledzenie przepływu zasobów wewnątrz sieci. Pomiar gęstości informujący o zakresie, w jakim węzły sieci wykorzystują możliwości nawiązania więzi z pozostałymi uczestnikami, pozwala określić, czy wszyscy uczestnicy sieci pozostają ze sobą w interakcji odwzajemnionej, czy też nieodwzajemnionej [Klimas 2013, s. 241]. 
Ostatni proponowany zakres badania sieci jako całości odnosi się do relacji organizacji z jej interesariuszami. Kultura jest zjawiskiem pozostającym w silnej współzależności ze środowiskiem zewnętrznym, zatem śledzenie np. przepływu informacji może sugerować przyczyny i kierunek zmian kulturowych.

Gdy przechodzimy na poziom mezo, wyłonienie podgrup w sieci skłania do poznania przyczyn takiego stanu rzeczy i wyabstrahowania kryteriów budowania klik czy klanów. W organizacji wielokulturowej daje podstawy do stworzenia mapy różnorodności kulturowej [Koźmiński 2004, s. 182]. Natomiast interpretacja struktury grafu pozwala na ocenę, czy wyszczególnione skupiska węzłów nawiązują relacje z innymi, za pośrednictwem ilu aktorów, czy też są klikami zamkniętymi, odizolowanymi od reszty.

Badanie sieci na najniższym poziomie - jednostki - pozwala szukać odpowiedzi na następujące pytania: na ile jednostka jest zdolna do współpracy (stopień węzła), czy uczestniczy w procesie dzielenia się wiedzą (pośrednictwo), czy aktor pozostaje w kręgu podzielanych wartości i norm (stopień węzła), czy też jest z niego wyizolowany.

Mając na względzie to, że węzłami mogą być organizacje i powracając znów do perspektywy organizacji sieciowej, ujęcie mikro pozwala na poznanie relacji pomiędzy uczestnikami sieci. Określenie pozycji (centralności) w strukturze powiązań między kooperantami umożliwia ocenę przewagi konkurencyjnej aktora nad innymi i określenie zakresu wpływu na kooperantów [Batorski 2008, s. 178], jak też zweryfikowanie prawdziwości założenia na temat równości aktorów w architekturze sieci [Sułkowski 2002, s. 89].

Powyższy opis stanowi jedynie wycinek możliwości zastosowania analizy sieci społecznych do badania kultury organizacyjnej. Jego zadaniem jest dostarczenie argumentów wskazujących na zasadność przyjęcia opisanej perspektywy badawczej, opartej na niestandardowej procedurze, a także ukazanie możliwości przeprowadzenia wielowymiarowej analizy zjawiska kultury.

\subsection{Podsumowanie}

Architektura współczesnych organizacji zmierza w kierunku zachowania elastyczności działania przez heterogeniczność kultury. Implikuje to zmianę podejścia do jej badania. Dotychczas stosowane powszechnie statyczne ujęcie organizacji, polegające na przypisywaniu jej atrybutów, staje się nieużyteczne ze względu na dynamikę zmian techniczno-społecznych zachodzących w jej obrębie i mających zasadniczy wpływ na sposób jej funkcjonowania. Należy zatem ograniczać tendencję do tworzenia uogólnień na rzecz badania specyfiki procesów właściwych danej organizacji [Sikorski 1998, s. 66-67]. 
Przyjęcie procesowego, dynamicznego podejścia do zjawiska kulturowego powściąga od instrumentalnego traktowania kultury w procesie zarządzania na rzecz poznania jej natury i przebiegu procesów ją konstytuujących [Sułkowski 2008, s. 19]. Metodyczne podstawy analizy sieci społecznych otwierają szerokie spektrum możliwości poznania zjawisk decydujących o charakterze danej kultury i wnioskowania zmierzającego do poszukiwania rozwiązań służących podnoszeniu efektywności działania danej sieci (organizacji).

\section{Bibliografia}

Barczak B., 2010, Analiza systemu zarzadzania strukturami sieciowymi, [w:] A. Stabryła (red.), Analiza i projektowanie systemów zarządzanie przedsiębiorstwem, Wyd. C.H. Beck, Warszawa.

Batorski D., 2008, Metody analizy sieci i ich zastosowanie w ewaluacji, [w:] A. Haber, M. Szałaja (red.), Środowisko $i$ warsztat ewaluacji, PARP, Warszawa.

Brzeziński J., 1980, Elementy metodologii badań psychologicznych, PWN, Warszawa.

Chmielewska A., Kołodziejczyk J., 2013, Zastosowanie socjometrii jako narzędzia badania ról zespołowych, „Współczesne Zarządzanie”, nr 2.

Czarnecki J. S., 2011, Architektura korporacji. Analiza teoretyczna i metodologiczna, Wyd. Uniwersytetu Łódzkiego, Łódź.

Dasgupta S., 2006, Encyclopedia of Virtual Communities and Technologies, Idea Group Inc. (IGI), Hershey.

Fryzeł B., 2005, Kultura korporacyjna. Poglady, teorie, zarzadzanie, Wyd. Uniwersytetu Jagiellońskiego, Kraków.

Griffin R. W., 2004, Podstawy zarządzania organizacjami, wyd. II zmien., Wyd. Naukowe PWN, Warszawa.

Hofstede G., 2000, Kultury i organizacje. Zaprogramowanie umystu, Polskie Wyd. Ekonomiczne, Warszawa.

http://www.orgnet.com.

Juszczyk S., 2001, Statystyka dla pedagogów, Wyd. Adam Marszałek, Toruń.

Kadushin Ch., 2012, Understanding Social Networks: Theories, Concepts, and Findings, Oxford University Press, New York.

Klimas P., 2013, Analiza sieciowa w naukach o zarzadzaniu, [w:] W. Czakon (red.), Podstawy metodologii badań w naukach o zarzadzaniu, wyd. II rozszerz. i uaktual., Oficyna a Wolters Kluwer business, Warszawa.

Knoke D., 2008, Social Network Analysis, Sage, Beverly Hills CA.

Kostera M., Glinka B., 2011, Od redaktora naukowego, „Problemy Zarządzania”, nr 2 (32), http://pz.wz.uw.edu.pl/pl/numer/antropologia-organizacji.

Koszelew J., 2011, Struktury danych do reprezentacji grafów. Wybrane algorytmy grafowe, http://www.asdpb.republika.pl/asdwyk7n.pdf (dostęp 8.04.2014).

Koźmiński A. K., 2013, Polskie laboratorium zarządzania, „Harvard Business Review Polska”, marzec.

Koźmiński A. K., 2004, Zarządzanie w warunkach niepewności. Podręcznik dla zaawansowanych, Wyd. Naukowe PWN, Warszawa.

Krupski R. (red.), 2003, Zarządzanie strategiczne. Koncepcje - metody, Wyd. Akademii Ekonomicznej, Wrocław. 
Kulpa-Ogdowska A., 2006, Właczeni i wyłaczeni z globalnej sieci. Społeczne konsekwencje rozwoju nowoczesnych technologii i konsumeryzmu, „Nierówności Społeczne a Wzrost Gospodarczy", $\mathrm{nr} 8$.

Marody M., Giza-Poleszczuk A., 2004, Przemiany więzi społecznych. Zarys teorii zmiany społecz$n e j$, Wyd. Naukowe Scholar, Warszawa.

McCulloh I., Armstrong H., Johnson A., 2013, Social Network Analysis with Applications, John Wiley \& Sons, Hoboken.

Paleczny T., 2007, Interpersonalne stosunki międzykulturowe, Wyd. Uniwersytetu Jagiellońskiego, Kraków.

Pryke S., 2012, Social Network Analysis in Construction, John Wiley \& Sons, London.

Przytula S., 2011, Problemy wielokulturowości w organizacjach międzynarodowych, „Problemy Zarządzania", nr 4 (34).

Rozkwitalska M., 2010, Bariery w zarzadzaniu międzykulturowym. Perspektywa filii zagranicznych korporacji transnarodowych, Wolters Kluwer, Warszawa.

Sikorski C., Bieńkowska J., 2014, Ewolucja zarzadzania w przestrzeni organizacyjnej, „Organizacja i Zarządzanie", nr 70.

Sikorski C., 1998, Ludzie nowej organizacji. Wzory kultury organizacyjnej wysokiej tolerancji niepewności, Wyd. Uniwersytetu Łódzkiego, Łódź.

Sikorski C., 2008, O zaletach stabej kultury organizacyjnej, „Zarządzanie Zasobami Ludzkimi”, nr 6.

Stępka P., Subda K., 2009, Wykorzystanie analizy sieci spolecznych (SNA) do budowy organizacji opartej na wiedzy, „E-mentor”, nr 1 (28).

Sułkowski Ł., 2002, Kulturowa zmienność organizacji, Polskie Wyd. Ekonomiczne, Warszawa.

Sułkowski Ł., 2008, Czy warto zajmować się kultura organizacyjna, „Zarządzanie Zasobami Ludzkimi”, nr 6.

Wasserman S., Faust K., 1994, Social Network Analysis: Methods and Applications, Cambridge University Press, Cambridge-New York.

Wysieńska K., 2012, O użyteczności analiz sieciowych w wyjaśnianiu procesów integracji migrantów, Fundacja Instytut spraw Publicznych, Warszawa.

Zbiegień-Maciąg L., 1999, Kultura w organizacji. Identyfikacja kultur znanych firm, Wyd. Naukowe PWN, Warszawa.

\title{
Jolanta Bieńkowska
}

\section{SOCIAL NETWORK ANALYSIS AS A METHOD OF ORGANISATIONAL CULTURE RESEARCH}

\author{
(Abstract)
}

Due to the intensive changes in the business environment, elements of an organization, including the organizational culture, are transformed. This implies the need to investigate new research methods in management, including those which capture dynamics as its dominant today's characteristic. The purpose of the chapter is to analyze social networks as a useful research method of organizational culture. It presents the method of social network analysis, a concise characteristic of evolution of organizational culture and proposals for the use of SNA for diagnosing organizational culture. 